\title{
FORMAÇÃO DE PROFESSORES: UM DIREITO QUE CONDUZ À EMANCIPAÇÃO? UMA IMPOSIÇÃO QUE LEVA À ALIENAÇÃO?
}

\author{
Eliane Tassi dos Santos
}

\section{RESUMO}

Esse trabalho resgata a historicidade das ideologias que envolvem as políticas educacionais num contexto nacional, porém, não dissociado do contexto global, por acreditar que este resgate é relevante para a compreensão do momento atual. Utilizando olhar crítico e objetivo quanto as políticas que regem a formação dos professores em seu nível inicial e continuada. Políticas essas ditadas pelo capitalismo e princípios neoliberais. Idealizadas e formuladas por organismos externos ao governo e sistema nacional mas acatadas e disseminadas pelos mesmos. Busca, então, expor também sobre a legislação vigente, que traz as diretrizes, objetivos e finalidades para essa formação, e sobre as discussões que envolvem o assunto e nos levam a questionar a política da eficiência na profissionalização, ou flexibilização do magistério, e o caráter intensificador da formação continuada, afim de levar o docente a alienar-se do contexto político e ideológico que o cerca.

\section{PALAVRAS-CHAVE}

Formação de professores; Políticas; Ideologias

\section{FORMATION OF PROFESSORS: A RIGHT THAT LEADS TO THE EMANCIPATION? NA IMPOSITION THAT LEADS TO THE ALIENATION?}

\begin{abstract}
This work rescues the historicidade of the ideologies that involve the educacional politics in a nacional context, however not dissociado of the global context, for believing that this rescue is excellent for the understanding of the current moment. Using to look at critic and objective how much te politics that conduct the formation of the professors in its initial and continued level. Politics these dictated by the capitalism and neoliberal principles. Idealized and spread for the same ones. Search, then to also display on the current law, that bring the lines of direction, objectives and purposes for this formation, and on the quarrels that involve the subject and in them leads to question the politics of the efficiency in the professionalization, or flexibilização of the teaching, and the character intensifier of the continued formation, similar to take the professor to become insane of the context politician and ideológivo that the fence.
\end{abstract}

KEYWORDS

Formation of Professors; Politics; Ideologies 


\section{ARTIGO Área Temática: Planejamento Educacional}

\section{INTRODUÇÃO}

Analisar e discutir sobre políticas educacionais requer entender como estas estão inseridas no contexto das políticas públicas de uma sociedade, para então entender como e porque é vista e efetivada a formação dos professores dessa sociedade.

É preciso antes, porém, entendermos os princípios que regem essa sociedade. E sendo nossa sociedade capitalista os princípios que a regem são, evidentemente, os do capitalismo, ou seja, do liberalismo, ou mais precisamente, do neoliberalismo. Pois, vivemos em uma sociedade movida pelo individualismo; pela busca da liberdade para agir em prol dos próprios interesses, independente do bem comum ou não; direito à propriedade de bens materiais, regado pelo consumismo desmedidos e inconseqüente; direito a igualdade de direitos perante a lei, infelizmente para usufruir dela em proveito próprio; e uma defesa e busca da democracia, que mascarada pelo discurso de todos terem o mesmo direito, é manipulada conforme os interesses de alguns.

Princípios estes que estabelecem os valores defendidos pela sociedade e que serão as bases das políticas estabelecidas. Políticas, consequentemente, propostas e formuladas por capitalistas liberais/neoliberais, para a manutenção de seus próprios interesses, e têm como articulador dessas políticas o aparato do Estado. “... o Estado atua como regulador das relações sociais a serviço da manutenção das relações capitalista em seu conjunto, e não especificamente a serviço dos interesses do capital - a despeito de reconhecer a dominação deste nas relação de classe”. (HOFLING, 2001, p. 33).

Aliás, o próprio Estado é dirigido e manipulado pelo capitalismo, pois não são capitalistas liberais/neoliberais a maioria dos nossos políticos?

No entanto, nossas políticas, em especial a educacional, que é o foco neste trabalho, não nasceram ao léu, ou, numa linguagem simples, "por obra e graça” dos nossos políticos. Não porque sejam menos ardilosos ou competentes que outros, ou mesmo porque são mais inocentes ou "humanos”, mas, simplesmente porque o contexto envolvido vai além das nossas fronteiras com este ou aquele país. 


\title{
ARTIGO Área Temática: Planejamento Educacional
}

\section{O BANCO MUNDIAL}

\begin{abstract}
Um banco Internacional, o Banco Mundial (BM), transformou-se, nos últimos anos, no organismo com maior visibilidade no panorama educativo global... O BM transformou-se na principal agência de assistência técnica em matéria de educação para os países em desenvolvimento (...) (TORRES, 1996, p. 125-126).
\end{abstract}

Com base no pensamento da autora, as propostas do BM para a educação é um conjunto de receitas prontas, elaboradas por economistas que nada tem a ver ou pouco entendem de educação para serem desenvolvidas com as massas, principalmente nos países ditos em desenvolvimentos, por educadores.

Considerando o óbvio, BM=Capitalismo=Liberais/neoliberais, as propostas buscam a qualidade para atender o mercado, desenvolver a competitividade em nome dessa mesma qualidade e aceitação das desigualdades, e principalmente, baixos custos. E, para isso propõem uma maior autonomia das escolas, inclusive, para resolverem seus "problemas" (achar recursos para resolvê-los). Defende, assim, o maior envolvimento e participação dos pais justamente pelo apoio financeiro que almeja. No entanto, deixa claro também sua opinião quanto a "supervisão" e controle dos passos pedagógicos e administrativos dos funcionários e professores ( cumprimento dos horários, por exemplo). Aliás, os professores, na visão do BM, não é “algo” muito importante, ou melhor, é um problema, uma vez que pensa, dá trabalho, reivindica e é muito caro. Para o BM, é muito mais aconselhável investir em livros, informatização, bibliotecas, valorizar a lição de casa ... porque assim, a sala estar mais cheia ou não, não fará diferença para o aprendizado do aluno. Para o BM o professor ganha muito e deve-se baixar os salários dos mesmos para investir mais nos outros recursos, como os que acabei de citar, inclusive propõem que os salários dos professores sejam vinculados ao desempenho e esses devem ser medidos através do rendimento dos alunos. Quanto a formação também há propostas diretas, por exemplo: priorizar a capacitação em serviço e recomenda que tanto a formação inicial quanto esta utilizem as modalidades a distância, por questão de custos, assim como, separar o método dos conteúdos, e afirma que o conhecimento da matéria é mais importante que o conhecimento pedagógico para o rendimento dos aluno.

Outra proposta que o BM defende e que para ele resolveria todas as questões é a Privatização. Pois, tira a responsabilidade financeira do Estado e muito favorece aos capitalistas. 
Mas, enquanto não se atinge a privatização, o BM propõem e “estimula” um maior (bem maior) investimento no Ensino Fundamental, já que, na sua visão, a Educação Infantil demora muito para dar retorno e o pouco que se investe é o suficiente para poupar gastos no fundamental, ao Ensino Médio deve-se oferecer cursos técnicos para garantir a mão de obra necessária, enquanto que investir na Educação Superior não é interessante, mesmo porque, não é conveniente ter muitos cidadãos bem formados e esclarecidos.

Por fim, para organizar e estabelecer suas propostas o BM se baseia e se "calça” em pesquisas. O problema é que também existem pesquisas que dizem o contrário de suas constatações mas que não são consideradas, além de as pesquisas que consideram serem tomadas como exemplo para qualquer lugar ou situação, mesmo com contextos e histórias diferentes.

\section{A LEGISLAÇÃO}

\section{PNE - Plano Nacional de Educação}

As primeiras idéias sobre um plano que tratasse da educação paro todo o território nacional aconteceram simultaneamente com a instalação da República Federal.

Em 1932, o "Manifesto dos Pioneiros da Educação”, documento que teve grande repercussão e motivou uma campanha que resultou na inclusão de um artigo específico na Constituição Brasileira de 16 de julho de 1934. O art. 150 declarava ser competência a União “fixar o plano nacional de educação, compreensivo do ensino de todos os graus e ramos, comuns e especializados. E coordenar e fiscalizar a sua execução, em todo o território do País”. Atribuía, em seu art. 152, competência precípua ao Conselho Nacional de Educação, organizado na forma da lei, a elaborar o plano para ser aprovado pelo Poder legislativo, sugerindo ao Governo as medidas que julgasse necessárias para a melhor solução dos problemas educacionais bem como a distribuição adequada de fundos especiais”.

A partir daí todas as Constituições incorporaram a idéia, implícita ou explicitamente.

\section{LDB - Lei de Diretrizes e Bases da Educação Nacional - Lei 9.394/96 de 20, dezembro 1996}

A nossa LDB demorou anos para ser aprovada, e quando o foi, há quem afirme que tivemos apenas “meia vitória, mas uma vitória”, e outros que dizem que "ela foi uma “decepção, mas não uma derrota”, isso por todas a brechas que ela deixou e deixa. 


\section{RESOLUÇÃO CNE/CP Nº 1, de 18 de fevereiro de 2002}

Institui Diretrizes Curriculares Nacionais para a Formação de Professores da Educação Básica, em nível superior, curso de licenciatura, de graduação plena.

A legislação atual, PNE-LDB-RESOLUÇÃO-2002, hora se completam, hora se contradizem.

\section{RESUMOS DAS DIRETRIZES DO PNE}

Qualificação dos Docentes; Melhoria da qualidade do Ensino; Valorização do magistério; Educação Continuada; Jornada organizada contemplando tempo com os alunos e tempo necessário para atividade complementares ao trabalho em sala de aula; Salário condigno; Compromisso social e político do magistério.

O PNE diz que na formação inicial é preciso superar a histórica dicotomia entre teoria e prática e o divórcio entre a formação pedagógica e a formação no campo dos conhecimentos específicos que serão trabalhados na sala de aula, e quanto a formação continuada diz que a mesma assume particular importância, em decorrência do avanço cientifico e tecnológico e de exigência de um nível de conhecimentos sempre mais amplos e profundos na sociedade moderna.

Assim, estabelece as seguintes diretrizes para os cursos de formação: sólida formação teórica; ampla formação cultural; atividade docente como foco formativo; contato com a realidade escolar antes da formação (estágios); pesquisa como princípio formativo; domínio das nova tecnologias; temas atuais; educação inclusiva; trabalho interdisciplinar; vivência de formas de gestão democrática do ensino; compromisso social e político; e conhecimento e aplicação das diretrizes curriculares.

A LDB, em seu art. 61 dispõem sobre os fundamentos da formação dos profissionais para o atendimento adequado aos diferentes níveis e modalidade de ensino e às características de cada fase do desenvolvimento do educando.

I - a associação entre teorias e práticas, inclusive mediante a capacitação em serviço;

II- o aproveitamento da formação e experiências anteriores em instituições de ensino e outras atividade.

No art. 62 explicita que para o exercício do magistério na educação infantil e nas quatro primeiras séries do ensino fundamental exige-se a formação mínima, oferecida em 
nível médio, na modalidade Normal, mas, no $§ 4^{\circ}$ do art. 87 diz que até o fim da Década da Educação, ou seja, até 20 de dezembro de 2007 (já que a mesma entrou em vigor 1 ano após sua promulgação), somente serão admitidos professores habilitados em nível superior ou formados por treinamento em serviço.

Seu art. 63 cita os institutos superiores de educação como um novo tipo de instituição de ensino responsável pela formação dos profissionais em Educação no Brasil. Eles deverão oferecer:

I - cursos formadores de profissionais para a educação básica, inclusive o curso normal superior...

II - programas de formação pedagógica para portadores de diplomas de educação superior que queiram se dedicar à educação básica;

III- programas de educação continuada...

Quanto a carga horária dos cursos fala em seu art. 65 que a formação docente, exceto para a educação superior, incluirá prática de ensino de, no mínimo, trezentas horas.

Mais uma vez torno a dizer, que é preciso que se tenha claro que direta ou indiretamente esta legislação é suporte para a política neoliberal que se encontra em nossa sociedade, pois, os aspectos e características dessa política demonstram os princípios defendidos pelo liberalismo/neoliberalismo, como veremos a seguir. Pois, a "década da Educação” representou o aprofundamento das políticas neoliberais. A educação e a formação de professores ganham, nessa década, importância estratégica para a realização das reformas educativas (FREITAS, 1999). Os 5 pontos dos governo Fernando Henrique para a melhoria do ensino público foram: descentralização das verbas, destinadas diretamente às escolas; criação do Sistema Nacional de Educação a Distância; melhoria dos livros didáticos; reforma dos currículos; e avaliação das escolas por meio de testes e premiações.

\section{PROFISSIONALIZAÇÃO OU FLEXIBILIZAÇÃO DO MAGISTÉRIO}

Por trás das palavras que descrevem as Diretrizes Nacionais para a formação dos professores, existem objetivos não descritos. Precisamos buscar "ler as entre-linhas” e questionar quais são esses objetivos.

Nos baseando em Freitas, 2002, é fácil identificar que, quando da Resolução de 1997 (Resolução CP n 04/97) o CNE aprova orientações para as novas diretrizes para os cursos de graduação inicia-se um processo de "flexibilização" da formação dos professores 


\section{ARTIGO Área Temática: Planejamento Educacional}

que contradiz a luta dos educadores pela profissionalização do Magistério que permeiam as discussões sobre o assunto em toda a ultima década.

Essa flexibilização pode ser traduzida como uma desvalorização indireta da própria profissão e do profissional da educação, fazendo com que esse profissional perca as referências e se sinta incerto quanto suas próprias lutas. Pois, ampliando os espaços de formação, ou seja, criando novos espaços, Institutos e faculdades, desvalorizam o papel das universidades. E, paralelamente coma flexibilização dos espaços, a flexibilização dos conteúdos cria uma dicotomia na formação dos professores que os divide em um lado “intelectuais”, a minoria capacitada com uma formação voltada para a reflexão crítica da realidade em que está inserido, juntamente com a competência teórica e capacidade de relacionar esta com a prática, e em outro lado os professores “técnicos”, formados para a prática, e entenda-se, prática orientada pelos valores e ideologia que regem os cursos que lhes são oferecidos.

Nossa hipótese é a de que as atuais políticas para graduação e também para a pós-graduação pretendem gradativamente retirar a formação de professores da formação científica e acadêmica própria do campo da educação, localizando-a em um novo campo' de conhecimento: da 'epistemologia da prática', no campo das praticas educativas ou da práxis. (FREITAS, 2002, p. 148).

Nestas reflexões encontramos respostas para algumas perguntas que são inevitáveis e que nos decepcionam tanto quando olhamos a nossa volta: Como um profissional graduado pode ter esta visão e esta prática? Como pode se manter indiferente a determinadas leituras, pesquisas e teorias? Como um profissional pode fazer a política dominante de forma tão natural e não se envergonhar disso?

A respostas estão claras: embora sejam graduados, os cursos são diferentes porque os objetivos implícitos são diferentes, portanto, conteúdos também diferentes.

Ainda quanto a flexibilização, não posso deixar de falar sobre a "liberdade"que é dada a Bachareis de outras áreas de adquirirem a licenciatura e tornarem a educação um "bico”. Aliás, outro fator da política da flexibilização que deixa claro, entre outras coisas, o caráter competitivo que querem fazer natural à educação e que não esconde suas bases neoliberais.

A retirada da formação de professores da ambiência universitária, a não obrigatoriedade da pesquisa, o rebaixamento das exigências em relação à autorização de centros universitários e universidades, aliados à separação dessas instituições dos cursos de bacharelado e, portanto, da produção de conhecimento nas áreas específicas, são fatores que vêm reforçando e confirmando a formação aligeirada em seu conteúdo e no tempo destinado à formação. (FREITAS, 2002, p.152-153). 
Podemos concluir que essa aligeiração é sem duvida mais um fator que agrava a desqualificação e desvalorização dos profissionais.

\title{
FORMAÇÃO CONTINUADA
}

A formação continuada deve ser uma

\begin{abstract}
continuidade da formação profissional, proporcionando novas reflexões sobre a ação profissional e novos meios para desenvolver e aprimorar o trabalho pedagógico; um processo de construção permanente do conhecimento e desenvolvimento profissional, a partir da formação inicial e vista integral, unilateral, produzindo-se a si mesmo, também se produz em interação com o coletivo. (ANFOPE, 1998 apud FREITAS 2002, p. 150).
\end{abstract}

Porém, nas políticas atuais ela vem reforçar o caráter conteudista da formação dos professores, resgatando uma problemática que já se pensava ter sido superada mas que está claramente impressa na formação dos professores, como pudemos constatar, quando os próprios cursos de formação de professores é dividido entre os que enfatizam os conteúdos e práticas, aliás, a maioria, e os que prezam pela pesquisa e reflexão, quase inacessíveis aos professores (por extinção dos próprios cursos ou impossibilidade, financeira ou não, dos próprios professores).

A Formação Continuada pode ser dividida entre a formação dos professores que estão em exercício mas sem a graduação “exigida” na legislação atual, ou seja, a nível superior, e os cursos oferecidos a esses mesmos professores em exercício a caráter de atualização ou especialização.

No entanto, conforme Freitas, 2002, o que vemos acontecer, em nome de se cumprir a lei, é um processo de certificação e/ou diplomação, e não qualificação e atualização dos professores para a prática do magistério. Pois, tanto para a graduação de professores em exercício como para a de atualização e especialização com cursos menores são utilizados recursos e métodos que assustam a quem busca e presa pela qualidade e seriedade dessa formação. Somos obrigados a presenciar, dentre tudo que já foi dito anteriormente, cursos a distancia com utilização de meios tecnológicos de comunicação que eliminam o contato e troca de experiências com os formadores capacitados e com demais professores graduandos e capacitandos. Aliás, esta é uma estratégia que requer menos custos, e não seria também uma maneira bastante eficaz para evitar a troca de reflexões conjuntas, união e organização dessa classe profissional? 
Além disso, é evidente a inversão de responsabilidades que estamos presenciando, pois, o que deveria ser responsabilidade dos estado, já que a legislação prevê a exigência dessa formação, acaba sendo obrigação dos professores, que muitas vezes acabam até pagando por esses cursos. O que a conseqüência é virar uma "bola de neve": considerando os baixos salários que ganham, procuram e aceitam cursos mais baratos, o que se resume em má qualidade e estruturas duvidosas. E, por pior que possa suar aos nossos ouvidos, muitas vezes fazem isso com consciência e em nome da competitividade e individualismo, que como já vimos estão implícitos em nossas políticas públicas neoliberais.

Sendo a Educação moldada pelos valores da sociedade, não é de nos espantar que os princípios do individualismo, competitividade e competência sejam tão valorizados também na Educação, por começar pela Formação dos professores. E são exatamente estes valores que se busca estimular quando se valoriza diplomas e certificados em nome da qualidade tão sonhada, mas, sabemos que estes não são garantia de qualidade.

Assim como, também sabemos que essa tão pregada, e escassa, qualidade é o carro chefe das políticas neoliberais para sua campanha em prol de manter seus princípios e valores.

E não podemos esquecer de que dentre seus princípios e valores os principais são os lucros e o acumulo do capital, e observe que programas multimídia e cursos em instituições privadas podem trazer muitos lucros a muitos capitalistas pouco interessados em educação. Não podem?

Estes cursos de formação continuada, principalmente os cursos de atualização, muitas vezes, servem como uma estratégia para intensificar os trabalho dos professores e garantir que estes sigam a filosofia que "devem”, sem que busquem por conta própria alternativas para suas indagações e questionamentos, ou seja, é mais uma forma de manipular a visão e prática do professor. Além do que, é preciso considerar a intenção de intensificar o trabalho docente, induzindo dos professores a dispensarem todo o tempo e energia para os trabalhos pedagógicos e dispersá-los das reflexões políticas que devem envolvê-los.

\section{O QUE VEMOS A NOSSA VOLTA?}

Até aqui vimos e analisamos a ideologia implícita nas políticas públicas, e em especial, na política educacional a qual estamos sujeitos atualmente. No entanto, é 
necessário que saibamos identificar os aspectos e características dessa ideologia que estão presentes nas políticas que estão mais próximas de nós, no nosso próprio local de trabalho e que fazem parte do todo, mesmo que tenhamos que trabalhar apenas com nossas impressões subjetivas.

Pois, nem sempre é fácil conseguir dados oficiais que nos ajudem a tirar conclusões sobre nossos questionamentos, mas, isso não deve ser um empecilho para continuarmos, ao contrário, é mais um fato que deve ser questionado. Pois, para concluir este trabalho tentei buscar informações oficiais sobre como a Prefeitura onde trabalho vê a formação dos seus professores, se ela tem uma política de formação para eles e como esta acontece e o que tenta envolver nessa capacitação, como é organizada e oferecida aos profissionais, quem são os formadores, como acontece a avaliação desses cursos e dos professores que deles participam, se há estímulos e incentivos para essa formação e qual é, a formação no dia-a-dia como é vista e como acontece ... Porém, a resposta que obtive é que para tentar ter acesso a essas informações seria necessário uma comprovação da finalidade destas informações para que fosse analisada. Resumindo, não obtive as informações, nem ao menos fui recebida. Mas, isso não me impede de analisar e questionar o que vejo.

Essa Prefeitura é uma das que fizeram o “acordo” com a Universidade de Campinas - Unicamp - para a realização do PROESF - Programa Especial para Formação de Professores em Exercício..., do qual faço parte. Aliás, um curso de qualidade reconhecida e comprovada, que optou por exemplo por ser presencial. Porém, de início, esta oportunidade não foi oferecida a todos os professores da rede, apenas aos efetivos. O que causa, no mínimo, curiosidade, já que, como é facilmente constatável, uma grande parte dos professores em exercício nesta rede são substitutos, apesar de alguns já estarem nesta situação a mais de 2 anos. Seria pelo fato de, também curiosamente, ter-se exigido dos professores que assinassem um determinado documento os “obrigando" a permanecerem na rede pelo o mínimo de 3 anos, o tempo de duração do curso? E onde isso leva? À garantia do retorno do que foi investido em cada um? A necessidade do professor estar ligado a rede, no mínimo enquanto concluir o curso, para o status "Nós investimos em Educação” ou para cumprir exigências legais?

É preciso lembrar que, coincidência ou não, muitas das substitutas e monitoras em exercício na rede, pressionadas pelo art. $87, \S 4^{\circ}$ da LDB que estabelece que “Até o fim da Década da Educação somente serão admitidos professores habilitados em nível superior ou formados por treinamento em serviço”, ingressaram no curso "Normal Superior” oferecido 
pela Faculdade Privada da cidade. Aliás, um curso que além de ser $100 \%$ pago pelos alunos, nem se sequer a disciplina de Política contempla no currículo.

Também é fácil constatar que é oferecido cursos de formação continuada a nível de atualização. Agora por exemplo, a rede esta oferecendo os cursos de LIBRAS, Nutrição e Língua Portuguesa “Letra e Vida”, entre outros.

O “Letra e Vida” é um curso que traz uma “nova” visão quanto a alfabetização, inclusive, parece ser bastante inovador a professores que ainda estão ligados a uma maneira mais tradicional de desenvolver sua prática, porém, podemos perceber claramente alguns dos aspectos já comentados: é nítida a mudança da postura política de alguns dos professores que participam deste curso, pois, antes envolvidos com esta discussão agora pouco dela falam (alienação) porque que estão as voltas com as problemáticas e "lições de casa” exigidas pelo curso, assim como em busca de novas atividades e de aplicá-las conforme o que lhes é passado (intensificação do trabalho). Neste curso, percebo pelos comentários, fica claro que o número de alunos por classe não é empecilho para que se desenvolva um bom trabalho docente, e fico com receio que se acredite que apenas a competência do professor a partir de um novo curso seja o suficiente para a efetiva aprendizagem dos alunos e que se estes não aprenderem é culpa exclusivamente do professor e passem a buscar a competência e qualidade do ensino como se fossem responsabilidade apenas do professor. Inclusive, a avaliação desse curso acontece na prática, com visitas da professora formadora na sala de aula das professoras que participam do curso (avaliação da competência e manipulação da prática do docente). Aliás, a formadora que é responsável por este curso é uma das professoras da rede que foi convidada a se capacitar para "formar" as outras professoras, o que exige menos custos e traz a certeza de que as coisas acontecerão como é o planejado (lucros e alienação na formação, mesmo cumprindo uma exigência da legislação).

E, quando se acredita na ideologia implícita nos cursos, passa-se a agir como se deseja e ainda competindo entre si mesmas, com um individualismo que só traz a desqualificação o trabalho.

Fica difícil, no entanto, dizer se o que acabei de expor é melhor ou pior que ouvir de uma colega que só esta fazendo o curso pelo diploma (certificação e competitividade).

Já a formação nas escolas, ou seja, o tempo que deve ser dispensado à preparação de atividades, avaliações, discussões e estudos em grupos, se resume em 1 hora e meia semanais para os professores das primeiras séries do Ensino Fundamental e em 1 hora, 
também semanal, para os professores de Educação Infantil. O que fere o PNE, uma vez que este documento prevê a dispensa de 20 a 25\% da carga horária para esta finalidade e podemos constatar que considerando a carga horária semanal sendo de 28 horas para o Ensino Fundamental e 23 horas para a Educação Infantil, teríamos que ter dispensado para esta finalidade no mínimo 7 e 6 horas semanais, respectivamente. Mas, existe também o fato de que permanecemos com alunos em sala de aula apenas 21,45 horas semanais no Fundamental e 20 horas na Educação Infantil, o que deixa uma diferença de 6,15 horas no Fundamental e 3 horas na Educação Infantil, mas que não são consideradas como sendo o direito previsto no PNE, uma vez que nos é sempre dito, quando questionamos alguma coisa: "vocês ganham por 28 horas e não trabalham”, "vocês ganham por 23 horas e não trabalham”. Então porque nós deveríamos considerar?

Quanto a valorização da formação inicial, não há. Apenas se considera o prérequisito para ingresso e o restante é ignorado.

A valorização da formação continuada fica por conta dos certificados que são convertidos em "pontos" para o professor, que lhe é útil nas remoções que queira participar ao final do ano letivo e na avaliação de 2 em 2 anos, que lhe rende o "Biênio" (um aumento de 5\% no salário base de 2 em 2 anos), mas que sofre a interferência de outros fatores como assiduidade e pontualidade, além de disponibilidade e participação no desenvolvimento de projetos da escola ou da rede. No entanto, pela própria exigência da legislação, um plano de cargos e carreiras está sendo elaborado e tende a modificar esta "valorização”.

\section{QUE ATITUDE TOMAR DIANTE DAS CONSTATAÇÕES?}

Diante do que vimos em torno das políticas educacionais e da formação de professores, a atitude que nos parece mais sensata seria desistir da profissão. No entanto, esta atitude nada mais faria do que colaborar com a ideologia dominante pelo simples fato de que ao desistir deixamos de ser um empecilho para suas armadilhas.

Por pior e mais difícil que possa parecer, o que nos resta é continuar sendo ao menos uma barreira que incomoda e impede que a situação piore ainda mais.

É preciso que tomemos as rédeas da nossa própria formação, que não acaba ao fim de um curso de graduação, especialização ou atualização. A formação dos professores é constante e contínua, e mais do que tudo, depende do que fazem com o que querem fazer 


\section{ARTIGO Área Temática: Planejamento Educacional}

com eles.

Podemos observar que os discursos dizem ser urgente as Reformas Educacionais, e o são, no entanto, a reforma mais urgente e realmente significativa é na identidade dos Professores. É preciso que eles próprios resgatem seus valores e suas responsabilidades, não apenas responsabilidades quanto aos alunos aprenderem ou não, mas quanto a responsabilidades com a políticas que os envolvem.

É preciso que os professores tenham plena consciência dos seus valores para que tenham força de lutar por seus direitos e valorização. É preciso que lutem contra a campanha ideológica que se lança contra suas capacidades e competências a fim de desmoraliza-los e subjulgá-los frente a sociedade e a eles próprios.

Os professores precisam que lhes sejam mostrados pequenos detalhes que engrandecem sua profissão e deixa claro porque são tão necessários e indispensáveis, e quanto a isso um bom exemplo são as palavras do Professor Celso Vasconcellos quando nos mostra que contra fatos há argumentos:

1. "O professor fica pouco tempo com o aluno, seu trabalho tem pouca chance de dar certo”.

Embora o tempo de permanência na escola seja limitado, há continuidade do contato e a ação educativa escolar é intencional e planejada, enquanto que a do meio é caótica.

2. "Atualmente, existe acesso muito facilitado à informação, o que faz com que o professor perca sua função”.

Informação é diferente de conhecimento, que exige mobilização, atividade, estabelecimento de relações, historicização, sistematização, categorização, etc. ou seja, pede mediação qualificada. Se antes faltava, agora há excesso de informação, exigindo ajuda para se fazer a seleção, a estruturação e a crítica.

3. "Há uma grande defasagem entre o conteúdo escolar e o científico”.

A escola trabalha basicamente com conteúdos alfabetizadores e estruturastes das várias áreas do conhecimento humano. Para que um sujeito possa se apropriar das contribuições de ponta (da nanotecnologia, p. ex.), precisa saber ler, escrever, calcular, situar-se no tempo e no espaço, etc., qual seja, das habilidades e competências básicas desenvolvidas pela escola.

4. “O ritmo de mudança da escola é muito lento em relação ao da tecnologia”. 
O ritmo da construção humana é outro, mais lento, em decorrência da própria complexidade muito maior. Estamos chegando a Marte, porém não conseguimos avançar muito em termos do enfrentamento da fome, da miséria ou até no controle do mosquito da malária em regiões pobres do planeta.

5. “Falta ‘aparato tecnológico’ na escola; muitos professores só dispõem de saliva e giz”.

A escola precisa sim desses aparatos, mas, existem necessidades humanas básicas não satisfeitas pela tecnologia - interação, afetividade, reconhecimento. Podemos ver pessoas pagando caro para aprender ouvir e contar estórias, uma das práticas mais arcaicas e “antitecnológicas” da humanidade.

6. "Existem muitos atrativos hoje fora da escola; fica difícil conseguir o interesse do aluno".

A escola, pela prática simbolizadora que desenvolve, pode trabalhar em muitos universos virtuais mas deve considerar o prazer que há no conhecer.

As pesquisas mostram que os alunos gostam da escola e até dos professores; o que não gostam são das aulas, mas estas podem mudar.

Inclusiva, com relação a mídia, temos vantagens significativa, como o contato direto, face a face, possibilidade de altíssima interatividade e da crítica.

7. “É o aluno quem aprende, portanto, o professor é dispensável”.

Efetivamente, o professor não pode aprender pelo aluno, mas, exerce um papel muito importante de mediação. Sem ele o aluno poderia levar anos para aprender sozinho.

8. “O importante é aprender a aprender”.

No entanto, se aprende a aprender aprendendo conteúdos concretos. Na escola, no projeto político-pedagógico há a definição de saberes considerados fundamentais para a constituição humana. Sem isto, o aluno correria o risco de não chegar a se apropriar destes relevantes conteúdos (conceituais, procedimentais e atitudinais).

9. “Atualmente o professor é tudo: pai, mãe, psicólogo, menos professor”.

Não, o professor não é pai, mãe, psicólogo, e não deve tentar ser, mas, Paulo Freire (1996: 163) foi cabal quando resumiu: "não sou terapeuta ou assistente social. Mas sou gente”. 


\section{CONSIDERAÇÕES FINAIS}

Este trabalho buscou mostrar o que envolve a formação de professores diante da ideologia que rege as políticas educacionais.

A partir dos fatos e considerações que foram feitas, espero ter contribuído com o leitor para que sua visão se ampliasse e fosse possível ver além do que nos mostram a legislação e o discurso de que a defende.

Espero contudo, que não fique apenas nas constatações mas que a partir daí tenhase uma nova postura. A postura de uma pessoa consciente e comprometida com sua realidade e profissão. E que busque, além de tudo a melhora de ambas.

Estou consciente e espero que todos estejam de que a batalha não é fácil, ao contrário, é árdua, pesada e cansativa. Por isso mesmo é imprescindível que todos estejam envolvidos e unidos. Já nos disseram Marx e Engels (1998, p. 65).

“Proletários de todos os Países, uni-vos!”

Então, peço licença para usar de pensamento e digo, com muita esperança em nossa classe: "PROFESSORES UNI-VOS”! Principalmente porque a mudança é necessária e urgente, se não, o que nos é dito como "certo" se torna "verdadeiro" e continuaremos nesse conformismo passivo.

Não estou sugerindo que abandonemos as salas de aula para subirmos nos palanques, nem tão pouco que façamos das escolas palanques, inclusive, "escola não é partido político” (FARIA, 2005. p. 86), mas que tenhamos uma postura politicamente consciente e coerente.

Estou sugerindo que é hora de nos assumirmos, de sairmos de cima do muro, de onde se fica esperando que uns ou outros “dêem a cara a tapa” e assumam sozinhos uma luta que é de todos os professores.

\footnotetext{
...o fato de que as diversas vontades individuais ...não atinjam o que querem, mas se fundam numa média coletiva, numa resultante comum, não se deve concluir que seu valor seja igual a zero. Pelo contrário, cada uma essas vontades individuais contribui para a resultante e, nesta medida, está incluída nela. (MARX; ENGELS, 1998 apud FARIA, 2005, p. 91).
}

Se não lutarmos pela nossa formação continuada e pela formação inicial daqueles que buscam ser professores, cada vez mais desvalorizada e menosprezada nossa profissão ficará. 
Façamos coro a “outra reforma” citada por Vera Maria Candau. Reforma que contradiz as reformas ditas novas, porém que não passam da mesmice que sempre foram, que servem apenas para ludibriar os menos esclarecidos. Essa “outra reforma” baseia-se na consciência das processos históricos e no pluralismo cultural, aliás, muito do que falamos neste trabalho, e tem como principais protagonistas os educadores. Inclusive, a própria crítica contra a escola pública e aos professores deve ser um estímulo a essa reforma.

\section{REFERÊNCIAS}

BRASIL. Conselho Nacional de Educação. Resoluções CNE: Resolução CNE/CP nº 1, de 18 de Fevereiro de 2002. Institui Diretrizes Curriculares nacionais para a Formação de Professores da Educação Básica, em nível superior, curso de licenciatura, de graduação plena. Brasília, DF, 2002.

Lei $\mathbf{n}^{\mathbf{0}}$ 10.172, de 9 de janeiro de 2001. Aprova o Plano Nacional de Educação e dá outras providências. Diário Oficial da União. Brasília, DF. 10 de jan. 2001.

Lei de Diretrizes e Bases da Educação Nacional, Lei $\mathbf{n}^{\circ} 9.394$ de 20 de dezembro de 1996. Estabelece as diretrizes e bases da educação nacional. Diário Oficial da União, Brasília, DF. 23 de dez. 1996.

CUNHA, L.A. A Educação e a construção de uma Sociedade Aberta.In.:

Educação e desenvolvimento social no Brasil. 5. ed. Rio de Janeiro: F. Alves, 1980. p. $25-60$.

FARIA, A. L. G. Ideologia no livro didático. 15. ed. São Paulo: Cortez, 2005.

FREITAS, H. C. L. Formação de professores no Brasil: 10 anos de embates entre projetos de formação. Educação e Sociedade, Campinas, v. 23, n. 80, set. 2002, p. 137 168.

Certificação docente e formação do educador: regulação e desprofissionalização. Educação e Sociedade, vol. 24, nº 85, ano 2003. Disponível em: http://www.cedes.unicamp.br. Acesso em: 10 jun. 2005.

HOFLING, E. M. Estado e políticas (públicas) sociais. Cadernos Cedes 55, ano XX, novembro/2001. p. 30 - 40.

SANTOS, L. L. C. P. Formação de professores na cultura do desempenho. Educação e Sociedade, v. 25, n. 89, ano 2004. Disponível em: http://www.cedes.unicamp.br. Acesso em: 10 jun. 2005.

TORRES, R. M. Melhorar a qualidade da educação básica? As estratégias do Banco 
Mundial. In: HADAD, S.; WARDE, M. J.; TOMMASI, L. O Banco Mundial e as Políticas Educacionais. São Paulo: Cortez, 1996. p. 125 -186.

VASCONCELLOS, C. S. Para onde vai o professor? Resgate do professor como sujeito de transformação, 10. ed. São Paulo: Libertad, 2005. 